\title{
Towards a Theory for Strategic Posture in New Technology Based Firms
}

\author{
Héctor Montiel Campos', Gerardo Haces Atondo², Madet Ruiseñor Quintero
}

\begin{abstract}
This paper elaborates a theory from the existing literature on subjects about entrepreneurship, strategy and innovation. Dubin's methodology approach is used in order to develop a theory that helps better understand the strategic posture adopted by a New Technology Based Firm in its competitive environment. The theory proposes the competitive context conditions as precedents of the dominant logic and the technology strategy, which, in turn, influence in the competitive behavior adopted by the new firm. An Entrepreneurial Orientation by the new firm, combined with very particular dynamic capabilities, improve the firm's performance. From the achieved performance, a feedback process to the strategic stance initiates. In addition to the theory, interaction laws, a set of propositions, as well as suggestions for future research projects are presented.
\end{abstract}

Keywords: theory building; new technology based firms; entrepreneurship; strategy; strategic posture.

'Business School and Economics, Universidad de las Américas Puebla, Sta. Catarina Mártir, Cholula, Puebla, México, 728 I0.

Tel. +52 (222)229 2479. E-mail: hector.montiel@udlap.mx ( Principal contact for correspondence

${ }^{2}$ Faculty of Commerce and Administration Victoria, Universidad Autónoma de Tamaulipas, Centro Universitario Victoria, Tamaulipas, México

${ }^{3}$ Consulting and Executive Education, Universidad de las Américas Puebla, Sta. Catarina Mártir, Cholula, Puebla, México• 


\section{Introduction}

The consideration of technology as a prevailing factor in firms' competitiveness has its origins during last century's 70's decade, both, in its macroeconomic and its microeconomic approach. This fact is the consequence of a series of changes that will be produced in the firm's environment and that will result in going from a relatively static and reasonably stable business environment, to an uncertain and turbulent growing environment (Solleiro and Castañon, 2005). The increase in business network and its regeneration through the replacement of some companies for others, are key indices to evaluate the impact technology brings with it in firms' competitiveness. One of the particular aspects that has earned special attention in subjects related to technological innovation, and the one this paper focuses on, deals with New Technology Based Firms (NTBF), understood as those which require the generation or an intensive use of technologies, some of them not totally mature, for the generation of new products, services or processes (Storey and Tether, 1998).

The relevance of these firms, as representative of the new economy due to their capacity to generate a high added value to the economic activity, has induced for them to be study object in the technology entrepreneurship field (Hindle and Yencken, 2004). Here lies the relevance of this research, whose objective is to propose a theory using Dubin's (1978) method, considering the most important variables that intervene in the strategic stance a NTBF adopts. The theory is built from a literature review by integrating different theoretical and empiric researches, mainly on entrepreneurship and strategy.

To achieve this goal, the research was structured as shown below. After the introduction, the Dubin (1978) methodology is described, which is used to elaborate the theory. Later, the main part of the paper is addressed, in which the different elements that make up the theory are developed, such as units, interaction, limits, operative conditions, and propositions. In a subsequent paragraph, future research projects are discussed, which can be performed through the theory that is developed. Finally, the conclusion of this project is presented.

\section{Dubin's methodology to theorize}

Dubin (1978) provides a methodology that helps theorizing from a literature analysis. The methodology consists of eight stages, which are: (I) units (concepts) from the theory, (2) laws of interaction (between the concepts), (3) theory's boundaries (the boundaries within the theory is expected to apply), (4) theory status (conditions under which the theory is operational), (5) theory's propositions (logical deductions about the operational theory), (6) empirical indicators (empirical measurements used to prove the propositions), (7) hypothesis (statements about forecasted values and links between the variables), and (8) research (the empiric test of forecasted values and links between the variables).

The first five stages of the methodology represent the methodology's structural components, and the last three stages represent the empiric validation process.Although the theorists must consider the eight stages of Dubin's methodology as an effective bet to build theories, it is important to mention that theory building and empiric research are generally considered as different stages within a research program, so each one of them requires different efforts to be conducted. Previous documents have already highlighted the usefulness of Dubin's (1978) method, by approaching different theoretical proposals (Conbere, 200I; Ardichvili, Cardozo and Ray, 2003; Lynham, 2002; Durán, San Martin and Montiel, 20I2).

\section{Elements of a strategic stance theory in NTBF Theory units}

Theory units are the concepts, or knowledge plots from which the theory is built. In order to determine the concepts that would be included in the theory, a review of literature about competitiveness in academic magazines was performed from the entrepreneurship and strategy approach taking the NTBF as the main element. The literature review shows different concepts, which, occasionally are mistaken with each other. These concepts correspond to central ideas and each author decides the theoretical perspective and the way in which the concept should be considered. The approach presented here may transmit the feeling of clearly identifiable processes, but in practice, this may not be so simple.

\section{New technology based firms}

The name NTBF is used to designate a new type of firm from the most recent stage of the industrial development in a generic way. One cannot properly say that behind this concept something homogeneous and with particular characteristics is defined; nevertheless, the definitions are unanimous when considered as firms that are based on the intensive domain of scientific and technological knowledge to keep their competitiveness for the first years of their existence (Autio, 2000).

The complexity when defining a NTBF is due to the fact that in its process of creation many factors intervene, which has raised a series of classifications. For example, for Storey andTether (1998) from the technology's origin, they are classified into university spin-offs, research spin-offs and corporate spin-offs. Steffensen, Rogers and Speakman (2000) clas- 
sify them into spontaneous and planned, depending on the motivation for the firm's creation. Birley (2002) classifies the NTBF into orthodox, hybrid and technological, according to the understanding and relationship of the entrepreneur with the technology source. Hague's and Oakley's (2000) classification is based on what is marketed, so they speak of direct spin-offs, which sell research results and indirect spin-offs, where the origin of the business idea is found in the acquired knowledge during the academic training, or else, in professional experience.

In general, a NTBF emerges when a person discovers a new technology with a high economic potential, but that is not relevant for the competitive strategy of the original organization, given that the created firm does not modify nor does it impact the strategy of the organization that gives rise to the technology (Thorburn, 2000). The former leads us to consider that the main objective of a NTBF, independently from its origin or classification, is to exploit some knowledge, technology, or a research result.

Although this type of firms constitute only a small percentage of the total of firms that make up the industry network, its relative importance in the economic activity of a region is greater since they are the ones that, by assuming a greater risk, accelerate the maturity of technologies and, definitively, feed the technological innovation. But they also fulfill another important task: increasing the business competition making other firms accelerate their transformation, increase their strategic alliances' network, and renovate their products or services.

\section{Dominant logic}

The concept of Dominant Logic (DL) was introduced in literature about strategy by Prahalad and Bettis (1986) and it refers to the way in which a manager conceptualizes the firm and makes strategic decisions. The manager's decision plays an important role in the DL, for the manager takes a series of preferences, opinions, and assumptions to each problem about how to lead the firm and how to compete in the market. This series of preferences, assumptions, and opinions is the manager's DL.

In the former input, Bettis and Prahalad (1995) conceive the $\mathrm{DL}$ as a mechanism that helps identify and process relevant information for decision making. This mechanism must be constantly enriched and adjusted to the changes of the environment in which the firm competes. The DL may give an explanation to why some firms anticipate and react more efficiently to changes in their environment than others in the same industry (Von Krogh, Erat and Macus, 2000). Under this lens, the DL may also limit the responsiveness on behalf of the firm when facing changes in the context. The DL acts as a lens which allows the manager to visualize the future and to identify the range of strategic options. If the results are positive, the $D L$ is confirmed, otherwise, it is questioned and it must change (Bettis and Prahalad, 1995).

Von Krogh, Erat and Macus (2000) talk about an external and internal conceptualization of the DL. The external conceptualization refers to the stance the manager takes in the markets in which he/she competes, which includes competitors, clients, and technology. The internal conceptualization refers to the degree to which the manager's beliefs, values, and assumptions are transmitted to the entire organization so that people and culture are transcendent issues. With time, a collective mentality may be accomplished which leads the organization to continually introduce new products in the market and to achieve a greater profitability. Meyer and Heppard (2000) refer to this as an entrepreneurial dominant logic. Now, the firm's size plays an important role in the establishment of a DL; the greater the firm, the more important a collective $D L$ is, unlike a smaller organization, where the firm's behavior is defined by the stance the manager adopts. (Bosma, Van Praag and Thurik, 2004).

\section{Technology strategy}

The establishment of a competitive strategy must be a priority for a firm, since objectives, and the way to achieve them, are established in it. In the case of a NTBF, the competitive strategy and the technology strategy are practically the same (Montiel et al., 2009). In this sense, it is important to identify the firm's core, as for to what it knows and not for the market it addresses. Hence, the technological strategy helps establish the policies, plans and procedures that help acquire, administer, and exploit technology and technological knowledge to achieve its business objectives (Montiel et al., 2009).

The resource-based view conceptualizes the firm as a knowledge system (Barney, 1991). This conceptualization characterizes the firm not only by its relationships and links with other organizations' systems, but also by its relations and links with other organizations' systems (Chesbrough, 2006). This idea materializes on the term "social capital" (Nahapiet and Goshal, 1998) with the purpose of recognizing that relationships are an asset, even when their value is hard to quantify. In other words, the firm must have an absorptive capacity, that is, there must be a certain level of technological knowledge for it to be able to recognize the potential of the new information or technology that improves its base knowledge. (Cohen and Levinthal, 1990).

Initially, the technological strategy must identify the industry in which the firm competes or will compete, taking into account that the competitive environments are more unstable 
every time. The technological strategy must be shaped considering the surge of new technologies and the changes in other firms' dominant and structural strategies. This sets the tone for the firm to be able to quickly react and to make the necessary adjustments for the new strategic commitment, so that the changes in the environment are technological opportunities. (Montiel et al., 2009).

\section{Entrepreneurial orientation and firm performance}

The concept of Entrepreneurial Orientation (EO) originates in literature about strategy and helps identify the competitive behavior that an organization adopts (Covin and Lumpkin, 20II). A firm's behavior can be classified along a continuum that goes from highly-conservative to highly-entrepreneurial and the position of the firm on this continuum describes its EO (Lumpkin and Dess, 1996). Miller (1983, p. 77I), who came up with the original ideas about this concept mentions that "An entrepreneurial firm is one that engages in product market innovation, undertakes somewhat risky ventures, and is first to come up with proactive innovations, beating competitors to the punch". From a more general approach, Lumpkin and Dess (1996) mention that the EO refers to the behavior a firm adopts in order to compete among the markets by offering new or current products.

From Miller's (1983) initial approach, literature has identified three EO's components - innovativeness, risk taking and proactiveness. Innovativeness refers to the support a firm gives to new ideas and the development of new products and services. Risk taking reflects the firm's tendency to carry on projects in which benefits are uncertain and, finally, proactiveness refers to the fact that the firm takes the initiative to seize new business opportunities in emerging markets. Lumpkin and Dess (1996) add the competitive aggressiveness and autonomy dimensions to the EO, nevertheless, most documents and research projects on EO have adopted Miller's three original components (Rauch et al., 2009).

Research on EO has found evidence that leads to propose that the firms that adopt an EO show a better performance (Su, Xie and Li, 20II). Nevertheless, Covin and Lumpkin (20II) argue that the results are not conclusive, therefore, it is necessary to continue the study of this relation. In this sense, literature also shows that a research document in which only the EO-firm relationship is analyzed, has limitations, due to the fact that this relation is much more complex and other factors intervene, both internal and external (Miller, 20I I).Although the EO stimulates a better firm's performance, it is necessary that this orientation is adequately directly within the organization, which implies adopting a new direction style which allows to seize business opportunities by using its resources and capacities, particularly those of intangible nature (Anderson and Eshima, 20I3).

\section{Dynamic capabilities}

The Dynamic Capabilities (DC) have their origin in the resource based-view, which establishes that the resources and capacities are heterogeneously distributed among firms and are imperfectly movable (Barney, 199I). From the resource based-view, Teece, Pisano and Shuen (1997) develop the DC's approach in order to explain how the combination of resources and competences can be developed, implemented, and protected. The authors define the DC as "the firm's ability to integrate, build, and reconfigure internal and external competences to address rapidly changing environments" (Teece, Pisano and Shuen, 1997, p. 516). From this, the DC reflect the firm's ability to reach a novel competitive advantage given its dependence on its trajectory and its market position.

On that same perspective, Eisenhardt and Martin (2000, p. I 107) affirm that the DC are "The firms' processes that use resources -specifically the processes to integrate, reconfigure, gain and release resources- to match and even create market change. Dynamic capabilities, thus, are the organizational and strategic routines by which firms achieve new resource configurations as markets emerge, collide, split, evolve, and die". The authors claim that the resources have no value to the firm if they are isolated, for which they reassert that the resources' potential value could only be available for the firm through its DC's idiosyncrasy. Likewise, former (Aramand and Valliere, 2012; Lin and Wu, 20I3) research projects have found that the firms with $D C$ show a better performance than firms that own only sole resources. The literature overview does not show a clear DC identification, nevertheless, Teece, Pisano and Shuen's (1997) proposal has been the most adopted when classifying coordination/ integration, learning, and reconfiguration/transformation capacities. The coordination/integration capacity requires the firm to be capable of coordinating or integrating efficiently internal activities - such as communication between the different units within the firm- and external activities- for example, strategic alliances, relationships with suppliers and clients, and technology transfer. The learning capacity refers to the process through which repetition and experimentation help make the task to be performed better and faster. Last, the reconfiguration/transformation capacity depends on the ability to scan the environment and to evaluate markets and competitors in order to calibrate the requirements for the change and to carry out the required adjustments ahead of the competition. The essence of Teece's, Pisano's and Shuen's (1997) proposal on DC, lies in the firm's organizational processes, which in turn, depend on the resources and the trajectory they have followed. 


\section{Significance of context}

The essential nature of competitiveness is changing several industries all over the world. Conventional sources of competitive advantage, such as economies of scale, are no longer enough. The challenges that evolve from the constantly changing conditions, provoke for flexibility, speed, innovation, integration, among other elements to be praised in decision making style (Solleiro and Castañon, 2005). The concept of hypercompetition captures the realities of the current competitive landscape, where disruption, globalization, and regulation are key. Under hypercompetition conditions, the stability premises in markets are replaced by instability and change, by a competition based on the rapid rise of the price-quality positioning, by the capacity of creating new knowledge, and by the establishment of advantages for being the first in the market (Mcnamara,Vaaler and Devers, 2003). Hypercompetition may generate conditions in the environment that will influence the firms' behavior, which hope to improve their position and, ultimately, their performance. Hostility and dynamism have been the two dimensions in the environment that have been consistently used to analyze their effect on the firm's performance. The limited availability of opportunities may generate a hostile competitive environment (Covin and Slevin, 1989) that, according to Khandwalla (1977), creates higher risk conditions and tension for the firms. On the other hand, the environment may be dynamic due to unpredictable changes in the environment and un- certainty. Dynamism also indicates uncertainty that erodes the management's ability to predict future events and their impact in the firm (Khandwalla, 1977).

\section{Laws of interaction}

The laws of interaction are those that describe the existing relation between the theory's concepts (units) and that show the cause-effect relations between the concepts, that is, they show the effect generated by the change of one or more concepts in the ones remaining (Dubin, 1978). These relations are those that can be observed in Figure I.

The theory begins with the influence that the context generally exercises on the competitiveness of the NTBF's which are part of the industrial network. Conditions such as globalization, disruption, and regulation can turn a competitive environment into a hostile and dynamic. These two issues influence in a special way when analyzed from the NTBF's perspective since, on this stage, the firm's goal is not scaling, but to learn and to identify a business model which allows the firm to survive.

A NTBF emerges as a response to a technological opportunity and is characterized by the simplicity of its organization, procedures, policies, communication, etc., among others. These issues make the founder-manager role to be trascendental, because his/her decision making greatly influences in

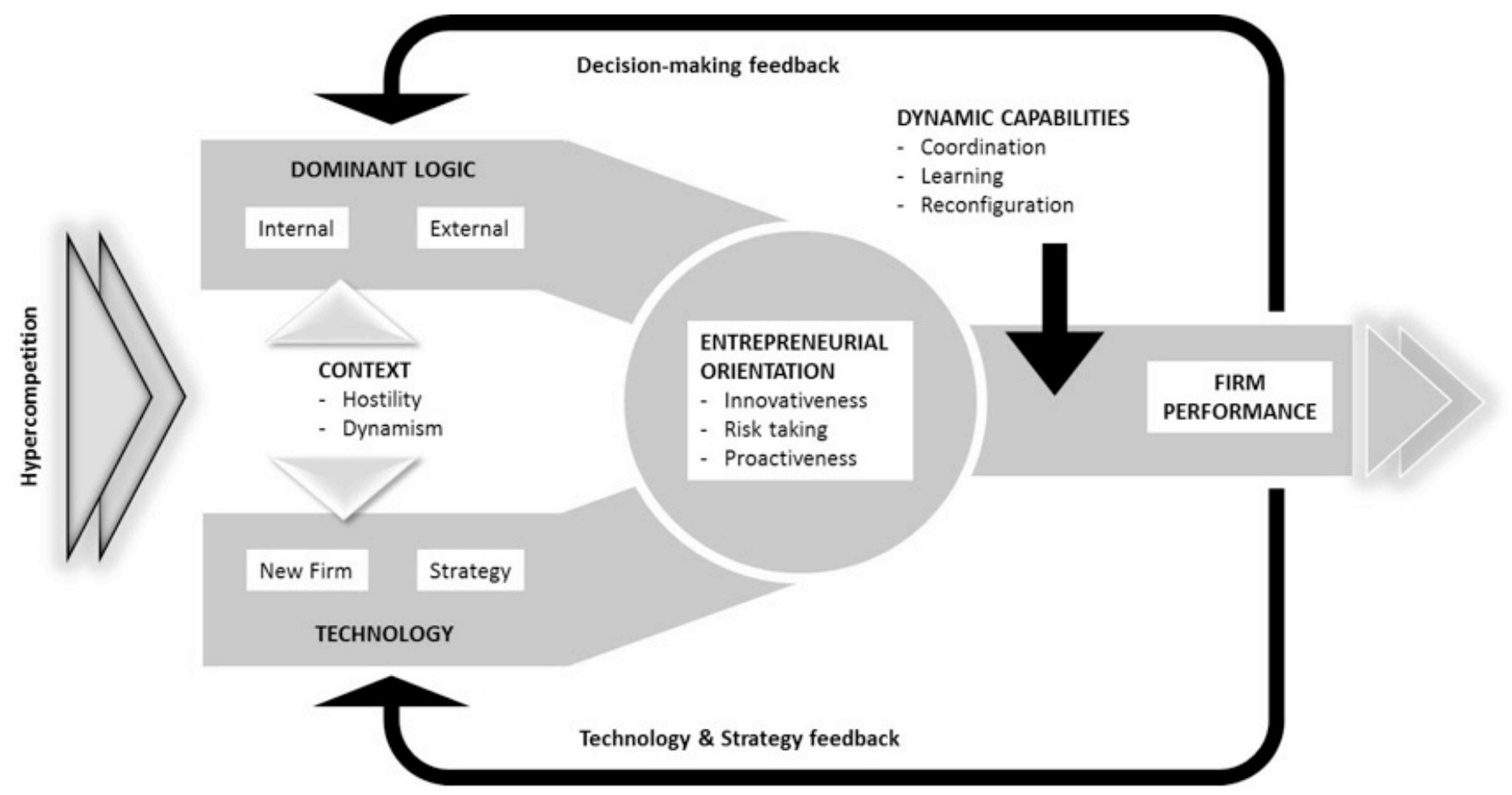

Figure I. A theory of strategic posture in NTBF

ISSN: 07 I8-2724. (http://www.jotmi.org)

Journal of Technology Management \& Innovation (c) Universidad Alberto Hurtado, Facultad de Economía y Negocios. 
the strategic stance adopted by the NTBF during their first years of operation. In other words, when the new firm's DL chooses a strategic posture, it is deciding, among different alternatives, the way to seize the technological opportunity. In this sense, the chosen technological strategy tells what the firm will carry out and how it wants to do it.

The DL and the technological strategy determine the intensity of the strategic posture in the NTBF. The firm may adopt a competitive behavior in which innovation, risk taking and proactiveness are privileged, that is, it may display an EO. On the other hand, the NTBF may be considered as a set of resources, which allows them to develop a series of singular capacities, which, in turn, may moderate the relation between their EO and their performance. Coordination, learning and reconfiguration are DC which allow the firm to adapt its strategic posture according to the context's demand.

Last, a firm's superior performance confirms its strategic posture, so it will try to keep the status quo. If the firm achieves a performance that does not meet the expectations, it motivates changes in its strategic posture, so it will be necessary to review its $D L$ and its strategy. This scheme allows the firm to continually review its performance and, in light of the results, make changes and adjustments in real time.

\section{Theory's boundaries}

Dubin (1978) mentions that the theory's boundaries establish the scope in which it is expected for it to be applied. A key issue in the literature about the organizational life cycle is that the prevalent problems within the firm change along different stages, as well as the challenges faced by the senior management (Bonn and Pettigrew, 2009). The initial stage in an organizational life cycle is known as start-up. It is precisely in this stage of the organizational life cycle where the theory here presented is expected to apply.

On top of the consideration of the initial stage in the organizational life cycle, there is technology.A technology start-up or a NTBF usually originates from the technological change, and in general, technology and firm's development happen at the same time. That is why the condition of being in the market for a few years and the strategic role of technology in identifying a business model make the NTBF a particular scope to develop a theory that explains its strategic posture in the face of competitive reality.

\section{Theory's status}

Dubin (1978) defines the theory's status as the condition in which all the theory's units take characteristic values that remain during time, regardless the time interval. All the theory's units have values that are determinant, that is, they are measurable and distinctive. From Dubin's (1978) proposal, for a state to represent as properly as possible the reality it intends to mold, it must be inclusive (that is, all the theory's units should be considered), persistent (the relationship between the units must be kept in such a way that it can be tested), and distinctive (all the units take unique values for a given state of the theory). The theory here developed satisfies the three requirements, as it includes the most important system's units (at least the units identified in the relevant literature about the subjects that intervene), the relations between the units described in Figure $I$ are durable and there is no value overlap between the units, as each one can be assigned a unique value.

\section{Propositions}

Propositions are statements that are logically derived from the theory and can be subjected to further empiric tests. The propositions derived from the theory are those developed below:

Proposition I:A hostile, competitive, and dynamic environment influences in the DL of a NTBF's founder-manager.

Proposition 2: A hostile, competitive, and dynamic environment determines a NTBF's strategic actions.

Proposition 3: The convergence of two domains - DL and technology strategy- is critical to define the competitive behavior a NTBF will adopt.

Proposition 4: A NTBF that shows a high EO will achieve a better performance.

Proposition 5:The NTBF's organization ensures its access to critical resources by establishing links with external actors.

Proposition 6:The relationship between the EO and a NTBF and its performance is moderated by its dynamic capabilities.

Proposition 7:The performance achieved by a NTBF generates adjustments or changes in decision making, both strategic and technological.

The propositions here presented are not exhaustive, nevertheless, each proposition directs the attention towards something that should be examined within the state of the proposed theory. 


\section{Future research}

The last three phases of Dubin's methodology are used to carry out an empiric research. In order to achieve this, the new research model should propose pointers that will make propositions verifiable, define hypothesis about possible values and links among the theory's units, and finally, carry out the empiric testing of the provided values and relations.

Some of the variables mentioned in the propositions already have their evaluation scales developed and validated, which is confirmed through research. In the case of the EO, Covin and Wales (2012) mention that Miller/Covin and Slevin's (1989) scale is the most used. Regarding performance, it has been evaluated in comparison with the main competitors' performance. This evaluation measurement has displayed good results before the absence of financial information (Wiklund and Shepherd, 2005). In a similar situation, empirical documents can be found about DL (Lampel \& Shamsie, 2000) and DC (Aramand and Valliere, 20I2; Lin and Wu, 2013), nevertheless these studies still face difficulties to make their concepts operative within the research. The different stages of development in the theory's involved variables lead to suggest that future research documents must adopt the appropriate methodologies for the pursued purpose of each research.

The theory this document proposes may give way to define a research program where individual documents are established that could use the propositions here developed as a starting point. Each proposition, or a group of them, could be a future research work. This should suggest the convenience of using different methods or approaches at the same time as suggested by Caracelli and Greene (1997). For instance, proposition 6 could pose an interesting methodology, in which a junction of quantitative and qualitative research took place. The EO-performance link could be quantitative, but the influence of the dynamic capacities on this link could be qualitative.

In this sense, although more resource-demanding, it could be a longitudinal methodology. Proposition 7 could cannel a research of this nature, by analyzing, in determined time intervals, the effects the firm's performance has on decision making In a similar perspective, On a similar perspective, proposition 5 could show how instrumental relations develop through time and how the firm obtains the required resources and capacities to achieve its goals.

Finally, it is important to mention that in the theory, the founder-manager and technology play a key role during the first years of the firm's life. The propositions here shown could not apply for an organization that does not comply with a NTBF's characteristics, an issue that should be considered in future research projects.

\section{Conclusion}

The outcome of this document was a theory using Dubin's (1978) method, but not a theory such as Porter's (1980), for example, which explains competitiveness in industries or the resource-based view to understand sources of competitive advantage within the firm (Barney, |991). Both theories possess maturity and strength in their arguments they have achieved after many years. This is not the case of the theory presented as the outcome of this project.

The theory exposed in this document is equivalent to a midrange theory in the sense attributed by Eisenhardt (1989), or else, an explanatory model under Yin's (2002) approach. Regardless the name that may be assigned to it, one should recall that every theory, midrange or explanatory model, is a simplification of the real experience. Langley (1999) mentions that the interaction of a relatively small number of variables can generate complexity if they are taken into account at the same time in the research of a phenomenon. Here is where the main challenge to develop the theory was found, which consisted in moving from a diversity of determining elements towards some type of theoretical understanding that does not lead to reality's wealth, dynamism, and complexity, but that is understandable and potentially useful for others.

There is hope that the theory here presented can be capable of transmitting the complexity possibly found when studying the strategic posture of a NTBF. The theory poses and ties propositions that help to better understand the competitive reality the NTBFs undergo. Within the context of this type of firms, technological change considerably influences on their strategic posture, and therefore, in their performance. The theory's proposal is that a TBNF's performance is not explained by the direct effect of a variable, but by different variables that may intervene at different times, whether directly or indirectly and that generate a continuous learning in the firm, in a way that it adjusts its strategic posture. 


\section{References}

ARAMAND, M., Valliere, D. (20I2). Dynamic capabilities in entrepreneurial firms: A case study approach. Journal of International Entrepreneurship, I0(2), I42-I57. DOI: I0.1007/ sl0843-0| 2-0088-3

ARDICHVILI, A., Cardozo, R., Ray, S. (2003). A theory of entrepreneurial opportunity identification and development. Journal of Business Venturing, I8(I), I05-I23. DOI: 10.1016/ s0883-9026(0I)00068-4

ANDERSON, B. S., Eshima, Y. (20I3). The influence of firm age and intangible resources on the relationship between entrepreneurial orientation and firm growth among Japanese SMEs. Journal of Business Venturing, 28(3), 4I3-429. DOI: 10.1016/j.jbusvent.20II.10.00I

AUTIO, E. (2000). Growth of technology-based new firms. In, Sexton, D. L., Landstrom, H. (eds.) The Blackwell Handbook of entrepreneurship. Blackwell, Oxford.

BARNEY,J. B. (1991). Firm resources and sustained competitive advantage. Journal of Management, I7(I), 99-I I0. DOI: I0.1177/014920639101700108

BETTIS, R. A., Prahalad, C. K. (1995). The dominant logic: Retrospective and extension. Strategic Management Journal, I6(I), 5-I4. DOI: I0.1002/smj.4250I60I04

BIRLEY, S. (2002). Universities, academics, and spinout companies: Lessons from Imperial. International Journal of Entrepreneurship Education, I (I), I-2I.

BONN, I., Pettigrew, A. (2009). Towards a dynamic theory of boards: An organizational life cycle approach. Journal of Management and Organization, I5(I), 2-16.

BOSMA, N., Van Praag, C. M., Thurik, A. R. (2004). The value of human and social capital investments for the business performance of start-ups. Small Business Economics, 23(3), 227236. DOI: I0.1023/b:sbej.0000032032.21192.72

CARACELLI,V. J., Greene, J. C. (1997). Crafting mixed-method evaluation designs. New Directions for Evaluation. 74, 1932. DOI: 10.1002/ev. 1069

CHESBROUGH, H. W. (2006). Open Innovation: The new imperative for creating and profiting from technology. Harvard Business School Press, Boston.

COHEN, W., Levinthal, D. (1990). Absorptive capacity:A new perspective on learning and innovation. Administrative Science Quarterly, 35(I), I28-I52. DOI: 10.2307/2393553
CONBERE, J. P. (200I). Theory building for conflict management system design. Conflict Resolution Quarterly, 19(2), 215-236. DOI: 10.1002/crq.3890190206

COVIN; J. G., Slevin, D. P. (1989). Strategic management of small firms in hostile and benign environments. Strategic Management Journal, I0(I), 75-87. DOI: 10.1002/ smj.4250I00I07

COVIN, J. G., Lumpkin, G.T. (20I I). Entrepreneurial orientation theory and research: Reflections on a needed construct. Entrepreneurship Theory and Practice, 35(5), 855-872. DOI: I0.1 I I I/j.1540-6520.20II.00482.x

COVIN, J. G.,Wales, W.J. (20I2). The measurement of entrepreneurial orientation. Entrepreneurship Theory and Practice, 36(4), 677-702. DOI: I0. I I I/j. I540-6520.20 I0.00432.x

DUBIN, R. (1978). Theory building. 2nd Ed. Free Press, New York.

DURÁN-ENCALADA, J.A., San Martin-Reyna, J. M., MontielCampos, H. (20I2). A research proposal to examine entrepreneurship in family Business. Journal of Entrepreneurship, Management and Innovation, 8(3), 58-77.

EISENHARDT, K. M. (1989). Building theories from case study research.Academy of management Review, 14(4), 532550. DOI: $10.5465 / \mathrm{amr}$. 1989.4308385

EISENHARDT, K. M., Martin, J. A., (2000). Dynamic capabilities: What are they? Strategic Management Journal, $2 \mathrm{I}(\mathrm{I0} / \mathrm{II})$, II05-II2I. DOI: | 0.1002/1097-0266(200010/II)21:10/II<1 105::aidsmj I33>3.0.co;2-e

HAGUE, M. T., Oakley, K. (2000). Spin-offs and start-ups in UK universities. CVCP Publication, London.

HINDLE, K., Yencken, J. (2004). Public research commercialization, entrepreneurship and new technology based firms: An integrated model. Technovation, 24(I0), 793-803. DOI: I0.1016/s0166-4972(03)00023-3

KHANDWALLA, P. N. (1977). The design of organizations. Harcourt Brace Jovanovich, New York.

LAMPEL, J., Shamsie, J. (2000). Probing the unobtrusive link: dominant logic and the design of joint ventures at general electric. Strategic Management Journal, 21 (5), 593603. DOI: $10.1002 /($ sici) 1097-0266(200005)21:5<593::aidsmj $100>3.3 . c 0 ; 2-s$ 
LANGLEY, A. (1999). Strategies for theorizing from process data. Academy of Management Review, 24(4), 69I-710. DOI: $10.2307 / 259349$

LIN, Y., Wu, L.Y. (20I3). Exploring the role of dynamic capabilities in firm performance under the resource-based view framework. Journal of Business Research, 67(3), 407-4I3. DOI: 10.1016/j.jbusres.2012.12.019

LUMPKIN, G. T., Dess, G. (1996). Clarifying the entrepreneurial orientation construct and linking it to performance. Academy of Management Review, 2I(I), I35-I73. DOI: 10.5465/amr.1996.960216I568

LYNHAM, S. A. (2002). Quantitative research and theory building: Dubin's method. Advances in Developing Human Resources,4(3), 242-267.DOI: I0.1 I 77/I5222302004003003

MCNAMARA, P.,Vaaler, M., Devers, C. (2003). Same as it ever was:The search for evidence of increasing hypercompetition. Strategic Management Journal, 24(3), 26I-278. DOI: 10.1002/ smj.295

MEYER, G. D., Heppard, K. A. (2000). Entrepreneurship as strategy: Competing on the entrepreneurial edge. Sage Publications, California.

MILLER, D. (1983). The correlates of entrepreneurship in three types of firms. Management Science, 29(7), 770-79I. DOI: 10.1287/mnsc.29.7.770

MILLER, D. (20I I). Miller (1983) revisited: A reflection on EO research and some suggestions for the future. Entrepreneurship Theory and Practice, 35(5), 837-894. DOI: I0.1 I I I/j.1540-6520.20II.00457.x

MONTIEL, C. H., Del Palacio, A. I., Solé, P. F., Nuño, P. J. P. (2009). Technology strategy and New Technology Based Firms. Journal of Technology Management and Innovation, 4(4), 42-52. DOI: I0.4067/S07 I8-27242009000400004

NAHAPIET, J., Ghoshal, S., (1998). Social capital, intellectual capital and organizational advantage. Academy of Management Review, 23(2), 242-266. DOI: I 0.5465/amr. 1998.533225

PORTER, M. E. (1980). Competitive strategy. Free Press, New York.

PRAHALAD, C. K., Bettis, R. A. (1986). The dominant logic: A new linkage between diversity and performance. Strategic Management Journal, 7(6), 485-50I. DOI: 10.1002/ smj.4250070602
RAUCH,A.,Wiklund, J., Lumpkin, G.T., Freese, M. (2009). Entrepreneurial orientation and business performance: Cumulative empirical evidence. Entrepreneurship Theory and Practice, 33(3), 76 I-788. DOI: I0.1 I I //j. 1540-6520.2009.00308.x

SOLLEIRO, J. L., Castañon, R. (2005). Competitiveness and innovation systems: The challenges for Mexico's insertion in the global context. Technovation, 25(9), 1059-1070. DOI: 10.1016/j.technovation.2004.02.005

STEFFENSEN, M., Rogers, E., Speakman, K. (2000). Spin-offs from research centers at a research university. Journal of Business Venturing, I5(I), 93-III. DOI: 10.1016/s08839026(98)00006-8

STOREY, D. J., Tether, B. S. (1998). Public policy measures to support new technology-based firms in the European Union. Research Policy, 26(9), I037-I057. DOI: I0.1016/S00487333(97)00058-9

SU, Z., Xie, E., Li, Y. (20I I). Entrepreneurial orientation and firm performance in new ventures and established firms. Journal of Small Business Management, 49(4), 558-577. DOI: I0.1III/j.1540-627x.2011.00336.x

TEECE, D. J., Pisano, G., Shuen, A. (1997). Dynamic capabilities and strategic management. Strategic Management Journal, 18(7), 509-533. DOI: 10.1002/(sici) I0970266(199708) I8:7<509::aid-smj882>3.0.co;2-z

THORBURN, L. (2000). Knowledge management, research spin-offs and commercialization of R\&D in Australia. Asia Pacific Journal of Management, 17(2), 257-275. DOI: I0.1023/A:I015861625956

VON KROGH, G., Erat, P., Macus, M. (2000). Exploring the link between dominant logic and company performance. Creativity and Innovation Management Journal, 9(2), 82-93. DOI: 10.1III/I467-869I.00160

WIKLUND, J., Shepherd, D. (2005). Entrepreneurial orientation and small business performance: $A$ configurational approach. Journal of Business Venturing, 20(I), 7I-9I. DOI: 10.1016/j.jbusvent.2004.01.00I

YIN, R. K. (2002). Case study research. Design and Methods. 3rd ed. Sage, California. 